\title{
UDO SCHWERTMANN
}

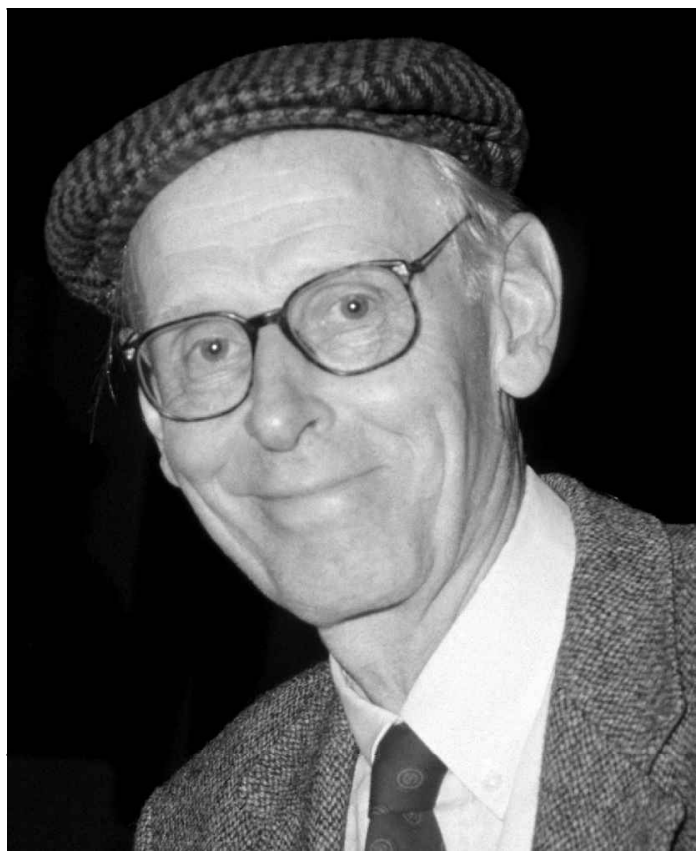

On 25 November 2002 Udo Schwertmann celebrated his 75th birthday. Even to those who are in regular contact with him, this is conceivable only with difficulty: every bit as vital as ever, he appears not to have aged at all - either mentally or physically. Following publication of an expanded second edition of the iron oxide 'recipe' book in 2000, he has now completed work on the second edition of the comprehensive iron oxide opus (both with Shelley Cornell). This is a momentous task, being more of a new book than an updated version of the first edition, and at the same time he is still producing scientific papers at a breathtaking rate.

Schwertmann's scientific studies have addressed a wide variety of problems in soil and clay science, and his bibliography - currently over 270 papers in scientific journals and book chapters, including articles on such diverse subjects as phyllosilicate formation and transformation in soils, the phosphate mineralogy and balance of soils, soil acidity and soil

DOI: $10.1180 / 0009855023740059$ erosion - bears witness to this. However, he is best known for his extensive work on iron oxides and oxyhydroxides (iron oxides sensu lato) formed in the weathering environment and their analogues synthesized in the laboratory. In 1959 he first applied the ammonium oxalate method to the identification of ferrihydrite (at that time still considered "amorphous iron oxide") in soils, and his 1964 paper on this method is now a citation classic. Much of this research has been concerned with the interrelation between soil chemistry and iron oxide mineralogy, in particular the well-known substitution of aluminium for iron in many iron oxides, and the inferences on the conditions of soil genesis that can be gathered from iron oxide mineralogy. Other highlights of Schwertmann's occupation with iron oxides include studies on the adsorption of various elements on these minerals and the ecological effects that iron oxides have upon soils. More recently his work on the precipitates generated by acid mine drainage - a serious environmental problem in many parts of the world - has led to the identification of the 'new' mineral schwertmannite, $\mathrm{Fe}_{8} \mathrm{O}_{8}(\mathrm{OH})_{6} \mathrm{SO}_{4}$. 
Schwertmann's vita has been repeatedly publicized, so rather than recounting chronological details or dwelling on specific periods of his career I will attempt to elucidate the recipe of his success.

Hardly anyone who has worked with Udo Schwertmann could avoid being captured by his infectious curiosity for all things in nature and his hearty joy of life. A favourable combination of this curiosity and the above-mentioned vitality, an exacting disposition associated with a high degree of self-criticism - uncommon enough these days and an exceptional ability to listen to and collaborate with people regardless of origin or rank has led to a worldwide network of friends - former students, research associates and guests - many of whom have worked with him at the Department of Soil
Science in Weihenstephan for periods ranging from days to decades and during their sojourn addressed a diversity of soil-related topics (although the vast majority had a more or less pronounced affinity to minerals, in particular the iron oxides). The latter fact is at least partly reflected in the contents of the present issue of Clay Minerals - a journal for which he served as Associate Editor for 16 years and for which he has been, and is still, a member of the Editorial Board since its 'Europeanization' in 1976 - that is dedicated to him. His cosmopolitan stance is reflected in the widespread locations of the colleagues who have agreed to contribute to this issue.

May he remain just as active, inquiring and critical for many years to come!

ENVER Murad 